\title{
Studies on the involvement of prostaglandins in implantation in the rat*
}

\author{
Christine A. Phillips $\uparrow$ and N. L. Poyser \\ Department of Pharmacology, University of Edinburgh, 1 George Square, \\ Edinburgh EH8 9JZ, U.K.
}

\begin{abstract}
Summary. Studies of prostaglandin (PG) production by uterine homogenates of rats in early pseudopregnancy and pregnancy showed that production of 6-oxo-PGF-1 $\alpha$, PGF-2 $\alpha$ and PGE-2 peaked on Day 5 of pseudopregnancy whereas only 6-oxo-PGF-1 $\alpha$ and PGE-2 peaked on Day 5 of pregnancy, the day of implantation. 6-Oxo-PGF-1 $\alpha$ was the major product in both reproductive states.

Indomethacin treatment of rats during early pregnancy caused a delay in implantation, a significant reduction in uterine weight, and a much reduced number or absence of implanted blastocysts in the uterus on Day 9. Plasma progesterone levels were also significantly lower in indomethacin-treated, pregnant rats. These findings support roles for prostaglandins in implantation, and in fetal development.
\end{abstract}

\section{Introduction}

The rat uterus exhibits variations in its prostaglandin (PG) synthesizing capacity during the oestrous cycle (Poyser \& Scott, 1980) and during pseudopregnancy (Fenwick, Jones, Naylor, Poyser \& Wilson, 1977). 6-Oxo-PGF-1 $\alpha$, reflecting prostacyclin (PGI-2) production, is the major PG formed together with smaller quantities of PGF-2 $\alpha$ and PGE-2. During the 4-day oestrous cycle, peak PG production occurs on Day 1 (oestrus), declines on Days 2 and 3, and starts to recover on Day 4. During pseudopregnancy, a similar trend is observed in PGF-2 $\alpha$ and PGE-2 production (6-oxo-PGF-1 $\alpha$ production has not yet been quantified), with a large peak occurring on Day 5, when PG production is higher than at any stage during the oestrous cycle. Day 5 is the day of implantation and so PG production in vitro by the rat uterus during early pregnancy and pseudopregnancy has been measured. In addition, the effects of indomethacin on implantation in the rat and the development of pregnancy up to Day 9 have been investigated.

\section{Materials and Methods}

Wistar rats were housed under controlled lighting conditions (lights on 08:00-20:00 h). Vaginal smears were taken daily and examined microscopically. Day 1 (oestrus) of the cycle was taken as the day of maximum cornification preceding the day of leucocytic infiltration. All rats used had shown regular 4-day cycles before being allocated to one of the following experiments.

Experiment 1. On the afternoon of Day 4 of the cycle females were caged individually with vasectomized males. They were removed at $12: 00 \mathrm{~h}$ on the following day, which then became Day 1 of pseudopregnancy. Mating was assumed to have taken place in the dark period, and

* Reprint requests to Dr N. L. Poyser.

† Present address: Department of Physiology, University of Queensland, St Lucia, Queensland, Australia 4067. 
pseudopregnancy was confirmed by the lack of subsequent oestrus and/or by the determination of peripheral plasma progesterone levels. Vaginal smears taken daily from 3 rats indicated that the length of pseudopregnancy (i.e. the period between two successive periods of oestrus) was 13 days in all 3 rats.

Other rats, lightly anaesthetized with ether, were bled by cardiac puncture at 10:00 h on each of Days 4-6 of pseudopregnancy (4 rats/day). The blood was withdrawn into a heparinized syringe (10 i.u. $/ \mathrm{ml})$ and centrifuged at $600 \mathrm{~g}$ for $5 \mathrm{~min}$. Plasma samples were stored at $-20^{\circ} \mathrm{C}$ before being assayed for progesterone. After killing the rats, by stunning then incising the neck, the uterus was removed, weighed, homogenized in $15 \mathrm{ml} \mathrm{Krebs}$ solution, incubated at $37^{\circ} \mathrm{C}$ for $60 \mathrm{~min}$, and the prostaglandins extracted, by methods previously described (Mitchell, Poyser \& Wilson, 1977; Fenwick et al., 1977). The solvent extraction procedure used gives recoveries of 90\% for PGF-2 $\alpha$ and PGE-2 and 65-75\% for 6-oxo-PGF-1 $\alpha$ (Poyser \& Scott, 1980). The results quoted are not corrected for recovery. The amounts of 6-oxo-PGF-1 $\alpha$, PGF-2 $\alpha$ and PGE-2 extracted from the incubates were measured by radioimmunoassay. 6-Oxo-PGF-1 $\alpha$ was also measured by gas chromatography-mass spectrometry.

Experiment 2. Females were caged individually with male rats of proven fertility on the afternoon of Day 4 of the cycle. Mating was confirmed by the appearance of spermatoza in the vaginal smear the next day (Day 1 of pregnancy). Blood samples for the measurement of plasma progesterone levels were obtained by cardiac puncture as in Exp. 1 for 5 rats/day on Days 3-7 of pregnancy. PG production by the uterine homogenates was measured as in Exp. 1 .

Experiment 3. Female rats were mated with fertile males as in Exp. 2. On Days 3-7 of pregnancy ( 3 rats/day), uteri were removed and each uterus was blotted dry, weighed and homogenized in $20 \mathrm{ml}$ absolute ethanol. The ethanolic homogenate was diluted with $20 \mathrm{ml}$ distilled water, the $\mathrm{pH}$ was lowered to 4.0 with $1 \mathrm{M}-\mathrm{HCl}$, and the PGs extracted by shaking 3 times with 2 volumes of ethyl acetate. The ethyl acetate fractions were combined and evaporated to dryness on a rotary evaporator at $45^{\circ} \mathrm{C}$. The extract was redissolved in $10 \mathrm{ml}$ ethyl acetate and stored at $-20^{\circ} \mathrm{C}$. PGs present were assayed by RIA as in Exp. 1 .

Experiment 4. Uteri from rats on the morning of Days 3-7 of pregnancy (3 rats/day) were removed, and divided into right and left uterine horns. One horn (a) was homogenized in $10 \mathrm{ml}$ Krebs' solution containing 0.25 $\mathrm{Ci}\left[{ }^{3} \mathrm{H}\right] \mathrm{PGF}-2 \alpha$ (sp. act. $160 \mathrm{Ci} / \mathrm{mmol}$; Radiochemical Centre, Amersham, U.K.). The second horn (b) was homogenized in $10 \mathrm{ml} \mathrm{Krebs'} \mathrm{solution} \mathrm{containing}$ $0.25 \mu \mathrm{Ci}\left[{ }^{3} \mathrm{H}\right] \mathrm{PGF}-2 \alpha$, unlabelled PGF-2 $\alpha(2 \mu \mathrm{g} / \mathrm{ml})$ and $2 \mathrm{~mm}$-nicotinamide-adenine dinucleotide $\left(\mathrm{NAD}^{+}\right)$. Both uterine horns were incubated at $37^{\circ} \mathrm{C}$ for $60 \mathrm{~min}$, and the PGs extracted as in Exp. 1. Each dry extract was dissolved in $0.5 \mathrm{ml}$ methanol and subjected to analysis by thin-layer chromatography by methods described previously (Maule Walker \& Poyser, 1978). The percentage metabolism of PGF-2 $\alpha$ was calculated from the radioactivity recovered after correcting the metabolites for the loss of a tritium atom from the carbon at position 15 .

Three reference plates onto which had been spotted $10 \mu \mathrm{g}$ PGF- $2 \alpha, 10 \mu \mathrm{g}$ 15-oxo-PGF-2 $\alpha$, and $10 \mu \mathrm{g} 13,14$-dihydro-15-oxo-PGF- $2 \alpha$ were also analysed. The $R_{\mathrm{F}}$ values of PGF-2 $\alpha$ and its main metabolites were $0.35,0.54$ and 0.59 , respectively.

Experiment 5. Three rats, mated as in Exp. 2, were taken at hourly intervals from $20: 00 \mathrm{~h}$ on Day 5 to $03: 00 \mathrm{~h}$ on Day 6 of pregnancy to determine the time of appearance of uterine 'dye reaction' sites indicative of the start of the implantation process. Each rat was anaesthetized with $25 \%$ urethane (May and Baker Ltd, Dagenham, U.K.) solution ( $7 \mathrm{ml} / \mathrm{kg}$, intraperitoneally). The jugular vein was cannulated, and $0.5 \mathrm{ml}$ of a $0.5 \%$ solution of Evans' Blue dye was injected into the vein. The rats were then killed $1 \mathrm{~h}$ later and the uterus examined for 'dye reaction' sites. The time of first appearance of the sites in our rats was 02:00 h on Day 6 of pregnancy.

Ten rats were injected subcutaneously with indomethacin $(3 \mathrm{mg} / \mathrm{kg}$, dissolved in $0.7 \mathrm{ml}$ polyethylene glycol) at 09:00 h and 17:00 h on Days 3 and 4 of pregnancy. Ten control prats 
were similarly injected with vehicle alone. Five rats in each group were examined at 02:00 or 10:00 h on Day 6 for the occurrence of the uterine 'dye reaction' sites by the above procedure. Peripheral plasma progesterone levels were also measured in these rats. (Evans' Blue dye did not cross-react with the antibody.) In addition, peripheral plasma progesterone levels were measured in other indomethacin-treated and control rats (5/group) on Days 7-9 of pregnancy at 10:00 h.

Experiment 6 . Rats were treated with indomethacin $(\mathrm{N}=11)$ or vehicle only $(\mathrm{N}=12)$ on Days 3 and 4 of pregnancy, as in Exp. 5, and were killed on Day 9. The uteri were removed, weighed and the appearance and number of implantation sites in each uterine horn were recorded.

\section{Assay procedures}

Radioimmunoassay of $P G s$ and progesterone. PGF- $2 \alpha$ was measured by an antibody raised in rabbits (Dighe, Emslie, Henderson, Rutherford \& Simon, 1975). Although the antibody does not distinguish between PGF- $2 \alpha$ and PGF- $1 \alpha$, it is probable that only PGF-2 $\alpha$ was being measured because the pseudopregnant rat uterus synthesizes very little PGF-1 $\alpha$ (Fenwick et al., 1977). The detection limit of the assay was $50 \mathrm{pg}$ per tube. PGE- 2 was measured using an antibody raised in rabbits and purchased from the Pasteur Institute (Paris). It has previously been tested and found suitable for use in this laboratory (Mitchell et al., 1977). Cross-reactivity with PGE-1 is low (6.6\%). The detection limit of the assay was $20 \mathrm{pg}$ per tube. 6-Oxo-PGF-1 $\alpha$ was measured by an antibody raised in rabbits (Dighe, Jones \& Poyser, 1978; Poyser \& Scott, 1980). The detection limit was $30 \mathrm{pg}$ per tube. The cross-reactivities of the 6-oxo-PGF-1a, PGE-2 antibodies with other prostaglandins have been reported by Poyser \& Scott (1980).

Plasma progesterone levels in rats were measured as described previously (Fenwick et al., 1977). The detection limit of the assay was $35 \mathrm{pg}$ per tube.

The inter-assay coefficients of variation for the PGF-2 $\alpha$, PGE-2, 6-oxo-PGF-1 $\alpha$ and progesterone radioimmunoassays were $8 \cdot 4,4 \cdot 2,6 \cdot 1$ and $7 \cdot 2 \%$ respectively. In each assay, biological samples were assayed in duplicate. If the coefficient of variation between the values obtained in each pair of results exceeded $15 \%$, then the biological sample was re-assayed. However, for most samples this intra-assay coefficient of variation between paired values was $<10 \%$.

Measurement of 6-oxo-PGF-1 a by gas chromatography-mass spectrometry (GC-MS). The radioimmunoassay results for 6-oxo-PGF-1 $\alpha$ production in Exps 1 and 2 were checked by GC-MS. Assays were carried out on a VG Micromass $7070 \mathrm{~F}$ double-focussing gas chromatogram-mass spectrometer, using the multiple ion detector unit. The column was packed with 3\% OV1 on Supelcoport (Supelco Inc., Belleforte, U.S.A.), the helium gas flow was 30 $\mathrm{ml} / \mathrm{min}$ and the column temperature was $260^{\circ} \mathrm{C}$. The methyl ester-butyloxime-trimethylsilyl (Me-BuO-TMS) derivative of 6-oxo-PGF-1 $\alpha$ was prepared as described previously (Fenwick et al., 1977).

To two-fifths of each biological sample were added $400 \mathrm{ng}$ 3,3,4,4-tetradeuterated6-oxo-PGF- $1 \alpha\left({ }^{2} \mathrm{H}_{4}\right.$-6-oxo-PGF-1) as internal standard. The Me-BuO-TMS derivative of the dried samples was then formed. One-quarter of each prepared derivative was injected into the apparatus and the $m / e$ ions at 491 and 495 , corresponding to 6-oxo-PGF- $1 \alpha$ and ${ }^{2} \mathrm{H}_{4}$-6-oxo-PGF-1 $\alpha$ (carbon value of 2 nd isomers $=26.2$ ), respectively, were monitored. Standard quantities of $0,12 \cdot 5,25,50,100$ and $200 \mathrm{ng} 6$-oxo-PGF- $1 \alpha$ and $100 \mathrm{ng}^{2} \mathrm{H}_{4}-6$-oxoPGF-1 $\alpha$ (as the Me-BuO-TMS derivatives) were also injected into the apparatus and the ions at $\mathrm{m} / \mathrm{e} 491$ and 495 were recorded. A standard curve (which in fact was a straight line) was obtained by plotting the ratio of the heights of the peaks produced by the ions at 491 and 495 against the standard quantities of 6 -oxo-PGF-1 $\alpha$. By finding this ratio for each sample, the amount of 6-oxo-PGF-1 $\alpha$ in the sample was determined from the standard curve. 


\section{Statistical tests}

The results, expressed as mean \pm s.e.m., were analysed by Student's $t$ test, the paired $t$ test or the analysis of variance, as appropriate.

\section{Results}

Experiment 1. The amounts of PGs produced by homogenates of pseudopregnant rat uteri are shown in Text-fig. 1. The ratio of production of 6-oxo-PGF-1 $\alpha$, PGF-2 $\alpha$ and PGE-2 was approximately $4: 2: 1$ for all 3 days studied; the amounts of each PG produced peaked on Day 5 . The values obtained for 6-oxo-PGF-1a by radioimmunoassay tended to be lower than those obtained by GC-MS (Table 1). However, the same trend was obtained by both methods.

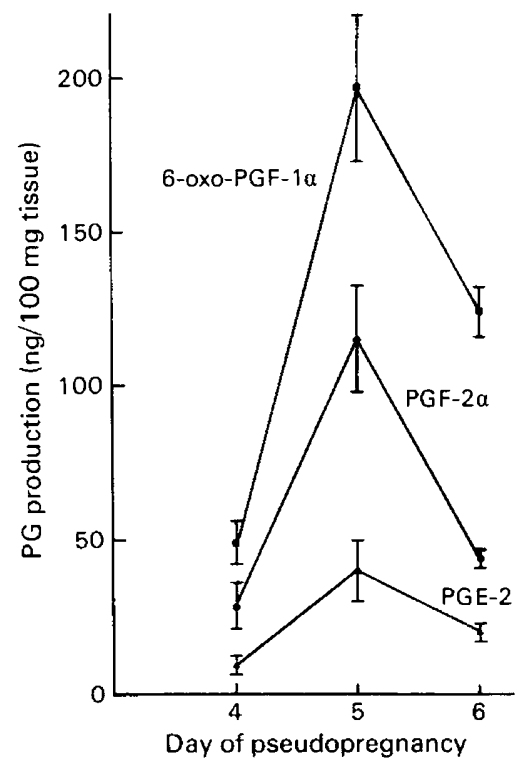

Text-fig. 1. Prostaglandin (PG) production (mean \pm s.e.m., for 4 observations) by uterine homogenates of rats in early pseudopregnancy. The amounts of 6-oxo-PGF-1 $\alpha$, PGF-2 $\alpha$ and PGE-2 produced were significantly higher on Day 5 than on Day $4(P<0.005, P<0.005$ and $P<0.05$, respectively $)$ or on Day $6(P<0.05, P<0.005$ and $P<0.05$, respectively).

Peripheral plasma progesterone concentrations (mean \pm s.e.m. for 4 observations) were $63 \pm 7,99 \pm 13$ and $92 \pm 7 \mathrm{ng} / \mathrm{ml}$ on Days 4,5 and 6 respectively, and agree with previously reported values (Pepe \& Rothchild, 1974).

Experiment 2. PG production by the rat uterus during early pregnancy is shown in Text-fig. 2. The production of PGE-2 and 6-oxo-PGF-1 $\alpha$ peaked on Day 5, as in pseudopregnancy. Uterine PGF- $2 \alpha$ production significantly increased from Days 2 to 3 of pregnancy, but then showed little variation until decreasing on Day 7. There was no peak equivalent to that for pseudopregnant rats on Day 5. 6-Oxo-PGF-1 $\alpha$ production was 5-6 times higher than PGF- $2 \alpha$ or PGE-2 production and values obtained by radioimmunoassay were similar to those obtained by GC-MS (Table 1).

Peripheral plasma progesterone concentrations (mean \pm s.e.m. for 5 observations) during early pregnancy were $33 \pm 4,53 \pm 4,94 \pm 20,70 \pm 9$ and $77 \pm 10 \mathrm{ng} / \mathrm{ml}$, on Days 3, 4, 5, 6 and 7 respectively, and agree with values reported previously (Wiest, Kidwell \& Balogh, 1968). 
Table 1. Comparison of values (mean \pm s.e.m.) for 6-oxoPGF- $1 \alpha$ production by rat uterine homogenates when measured by radioimmunoassay (RIA) and gas chromatography-mass spectrometry (GC-MS) in Exp. 1 $(\mathrm{N}=4)$ and $\operatorname{Exp} .2(\mathrm{~N}=5)$

\begin{tabular}{clcr}
\hline & & \multicolumn{2}{c}{$\mathrm{ng} / 100 \mathrm{mg}$ tissue } \\
\cline { 3 - 4 } Day & \multicolumn{1}{c}{ State } & RIA & \multicolumn{1}{c}{ GC-MS } \\
\hline \multirow{2}{*}{3} & Pregnant & $211 \pm 41$ & $226 \pm 32$ \\
4 & Pregnant & $267 \pm 5$ & $245 \pm 10$ \\
& Pseudopregnant & $49 \pm 7$ & $79 \pm 17$ \\
5 & Pregnant & $346 \pm 46$ & $309 \pm 12$ \\
& Pseudopregnant & $198 \pm 25$ & $260 \pm 77$ \\
6 & Pregnant & $230 \pm 47$ & $169 \pm 40$ \\
& Pseudopregnant & $124 \pm 8$ & $161 \pm 13$ \\
\hline
\end{tabular}

Only values for Day 6 of pseudopregnancy are significantly different $(P<0.005)$. Production during pregnancy was greater than during pseudopregnancy on Days $4(P<0.005), 5(P<$ $0.01)$ and $6(P<0.05)$ when comparing the RIA results. This difference only remains significant on Day 4 if the GC-MS values are compared.

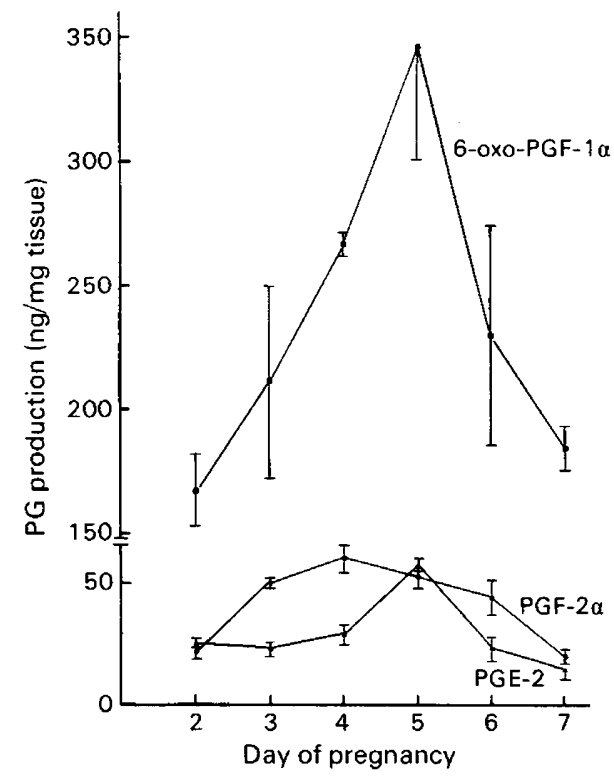

Text-fig. 2. Prostaglandin (PG) production (mean \pm s.e.m., for 5 observations) by uterine homogenates of rats in early pregnancy. The amounts of 6-oxo-PGF- $1 \alpha$ and PGE-2 produced were significantly higher on Day 5 than on Day $4(P<0.01$ and $P<0.005$, respectively) or on Day $6(P<0.05$ and $P<0.005$, respectively). The amount of PGF-2 $\alpha$ produced significantly increased between Days 2 and $3(P<0.01)$ and significantly decreased between Days 6 and 7 $(P<0.01)$.

Experiment 3. Uterine tissue levels of 6-oxo-PGF-1 $\alpha$, PGF-2 $\alpha$ and PGE-2 on Days 3-7 of pregnancy were low (Table 2). A significant drop $(P<0.05)$ occurred in the PGF-2 $\alpha$ and 6-oxo-PGF-1 $\alpha$ levels on Day 6. 
Table 2. Concentrations ( $\mathrm{ng} / 100 \mathrm{mg}$ tissue, mean \pm s.e.m., for 3 observations) of prostaglandin (PG) E-2, PGF- $2 \alpha$ and 6-oxo-PGF- $1 \alpha$ in rat uterus during early pregnancy

\begin{tabular}{|c|c|c|c|c|c|}
\hline & \multicolumn{5}{|c|}{ Day of pregnancy } \\
\hline & 3 & 4 & 5 & 6 & 7 \\
\hline PGE-2 & $1.1 \pm 0.5$ & $1.8 \pm 0.8$ & $1.5 \pm 0.4$ & $0.9 \pm 0.2$ & $1.0 \pm 0.1$ \\
\hline PGF-2 & $2.2 \pm 0.5$ & $3.0 \pm 1.0$ & $3.0 \pm 0.6$ & $0.9 \pm 0.2^{*}$ & $2.2 \pm 0.3$ \\
\hline 6-oxo-PGF-1 $\alpha$ & $1.8 \pm 0.6$ & $3 \cdot 1 \pm 1 \cdot 3$ & $3.3 \pm 0.6$ & $1.6 \pm 0.4 \dagger$ & $3 \cdot 6 \pm 0.5$ \\
\hline
\end{tabular}

* Significantly lower than Day 5 value $(P<0.05)$.

+ Significantly lower than Day 7 value $(P<0.05)$.

Experiment 4. The pregnant rat uterus metabolized PGF $-2 \alpha\left(R_{\mathrm{F}}=0.35\right)$ into a mixture of 15-oxo-PGF- $2 \alpha\left(R_{\mathrm{F}}=0.54\right)$ and 13,14-dihydro-15-oxo-PGF- $2 \alpha\left(R_{\mathrm{F}}=0.59\right)$. Because these 2 metabolites were very close on the thin-layer chromatographic plate, the percentage metabolism of PGF-2 $\alpha$ into these products is expressed as a single figure (Table 3). Metabolism of PGF-2 $\alpha$ was low during early pregnancy. Assessment by analysis of variance showed that the addition of $\mathrm{NAD}^{+}$and of excess PGF- $2 \alpha$ did not affect metabolism. However, metabolism significantly increased with time $(P<0.001)$.

Table 3. Percentage metabolism (mean \pm s.e.m., for 3 observations) of $\left[{ }^{3} \mathrm{H}\right]$ prostaglandin $\mathrm{F}-2 \alpha$ by uterine homogenates from early pregnant rats

\begin{tabular}{lccccr}
\hline \multicolumn{5}{c}{ Day of pregnancy } \\
\cline { 2 - 6 } & 3 & 4 & 5 & 6 & \multicolumn{1}{c}{7} \\
\hline Without NAD $^{+}$ & $2 \cdot 8 \pm 0.2$ & $3.0 \pm 1 \cdot 1$ & $2.4 \pm 0.8$ & $6.9 \pm 2 \cdot 1$ & $9.4 \pm 1.0$ \\
${\text { With } 2 \mathrm{mM} \mathrm{NAD}^{+}}$ & $3.5 \pm 1.5$ & $4.4 \pm 1 \cdot 1$ & $4.8 \pm 0.6$ & $7.8 \pm 0.5$ & $11.6 \pm 0.9$ \\
$+2 \mu \mathrm{g} \mathrm{PFF}-2 \alpha / \mathrm{ml}$ & & & & & \\
\hline
\end{tabular}

Metabolism significantly increased with time $(P<0.001)$. The addition of NAD ${ }^{+}$and excess PGF- $2 \alpha$ had no significant effect.

Experiment 5. Pregnant rats treated with indomethacin had no uterine 'dye reaction' sites when examined at 02:00 $\mathrm{h}$ on Day 6, in contrast to control rats (Table 4). Some indomethacin-treated rats showed small dark spots in the endometrium which may have been blood clots. Pregnant rats treated with indomethacin and examined at 10:00 h on Day 6 had numbers of 'dye reaction' sites/uterine horn similar to those of control rats.

Table 4. Effect of indomethacin treatment $(3 \mathrm{mg} / \mathrm{kg}$ subcutaneously at 9:00 $\mathrm{h}$ and 17:00 h on Days 3 and 4) on 'dye reaction' sites and implantation sites in rats

\begin{tabular}{|c|c|c|c|c|}
\hline Treatment & $\begin{array}{l}\text { No. of } \\
\text { rats }\end{array}$ & $\begin{array}{c}\text { Time of } \\
\text { examination }(h)\end{array}$ & $\begin{array}{l}\text { No. of sites } \dagger / \\
\text { uterine horn }\end{array}$ & $\begin{array}{c}\text { Uterine wt } \\
\text { on Day } 9(\mathrm{mg})\end{array}$ \\
\hline \multicolumn{5}{|l|}{ Experiment 5} \\
\hline Control & 5 & $02: 00$ & $5.6 \pm 0.6$ & - \\
\hline Indomethacin & 5 & $02: 00$ & $\overline{0}$ & - \\
\hline Control & 5 & $10: 00$ & $5 \cdot 5 \pm 0.4$ & - \\
\hline Indomethacin & 5 & $10: 00$ & $5.8 \pm 0.4$ & - \\
\hline \multicolumn{5}{|l|}{ Experiment 6} \\
\hline Control & 12 & $10: 00$ & $5 \cdot 5 \pm 1 \cdot 2$ & $912 \pm 104$ \\
\hline \multicolumn{5}{|l|}{ Indomethacin } \\
\hline (i) & 7 & $10: 00$ & 0 & $374 \pm 31^{*}$ \\
\hline (ii) & 4 & $10: 00$ & $2 \cdot 6 \pm 1 \cdot 1^{*}$ & $349 \pm 65^{*}$ \\
\hline
\end{tabular}

* Significantly lower than in control groups $(P<0.01)$.

$\dagger$ 'Dye reaction' sites on Day 6 in Exp. 5 and implantation sites on Day 9 in Exp. 6. 


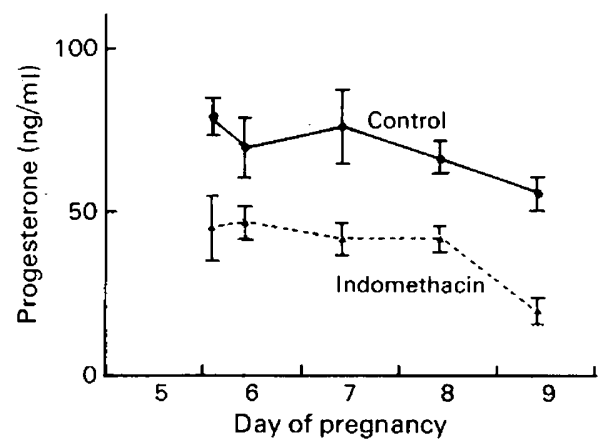

Text-fig. 3. Peripheral plasma progesterone concentrations (mean \pm s.e.m., for 5 observations) in control and indomethacin-treated ( $3 \mathrm{mg} / \mathrm{kg}$ Days 3 and 4 , twice/day) rats measured at 10:00 $\mathrm{h}$ on each day of pregnancy and also at $02: 00 \mathrm{~h}$ on Day 6. Values are significantly lower $(P<0.05)$ in indomethacin-treated rats.

Peripheral plasma progesterone concentrations in pregnant rats treated with indomethacin (Text-fig. 3) were significantly lower than those in control rats at all times studied.

Experiment 6. Indomethacin treatment reduced the numbers of implantation sites/uterine horn and uterine weight (Table 4). When implantation had occurred, the implanted blastocysts were visibly smaller than in control rats, and in 2 of the 4 animals were bunched at the cervical end of the uterine horns. Control rats had evenly spaced implanted blastocysts.

\section{Discussion}

The major PG formed by uterine homogenates of rats early in pseudopregnancy and pregnancy was 6-oxo-PGF-1 $\alpha$, the stable metabolite of prostacyclin (PGI-2); production peaked on Day 5 in both reproductive states. Uterine PGE-2 production was lower both during pregnancy and pseudopregnancy, again peaking on Day 5. Uterine PGF-2 $\alpha$ production was also lower than 6-oxo-PGF-1 $\alpha$ production, but only peaked on Day 5 in pseudopregnant rats. There was no increase on this day in pregnant rats.

Changes in PG production are probably due to changes in PG synthesizing capacity of the tissue, for 2 reasons. Basal levels of PGs in the uterus are low, therefore fresh synthesis of prostaglandins must have taken place during incubation. Metabolism of PGF-2 $\alpha$ by the pregnant uterus was also low and showed no difference on Day 5, so changes in PG metabolism could not account for changes in PGF production. Metabolism of PGF-2 $\alpha$ by the pregnant rat uterus did show a small increase on Days 6 and 7, as reported by Flower (1976). Metabolism of PGE-2 and PGI- 2 by the pregnant rat uterus is also likely to be low as the same enzymes are involved. Oestradiol stimulates an increase in PG production by the uterus (Naylor \& Poyser, 1975; Ham, Cirillo, Zanetti \& Kuehl, 1975; Wlodawer, Kindahl \& Hamberg, 1976). The increase in plasma concentration of oestradiol early on Day 4 (Shaikh, 1971) may therefore be responsible for the increase in ability of uterine homogenates to produce PGs on Day 5. Treatment of pseudopregnant rats with tamoxifen on Day 2, in doses which inhibit ovarian oestradiol output, significantly decreases PG production by the uterus on Day 5 (Fenwick et al., 1977). However, in the pregnant rat, the ovary may not be the only source of increased oestradiol output. $\Delta^{5}-3 \beta$-Hydroxysteroid dehydrogenase and oestradiol-17 $\beta$-hydroxysteroid dehydrogenase activities are first detectable in the blastocyst on Day 4, peak on Day 5 and decline on Day 6 (Dickmann \& Dey, 1974; Dey \& Dickmann, 1974). If these changes in enzyme activities reflect changes in steroid synthesis, oestradiol and other steroid hormones synthesized by the blastocyst may alter uterine PG production. The presence of the blastocyst certainly does appear to affect 
uterine PG synthesis, since PGF-2 $\alpha$ production by the pregnant uterus is lower on Day 5 compared with production by the pseudopregnant uterus.

These studies suggest a role for PGI-2 and PGE-2 in implantation in the rat. The levels of these 2 PGs are higher at the implantation site than in other uterine areas (Kennedy, 1977; Kennedy \& Zamecnik, 1978). Changes at the site of implantation have been linked to an inflammatory process (Horan, 1971). Acute inflammation is characterized by vasodilatation and increased vascular permeability. PGE-2 and PGI-2 are known vasodilators (Moncada, Gryglewski, Bunting \& Vane, 1976) while PGE-2, but not PGF-2 $\alpha$ or PGI-2, has been found to increase endometrial vascular permeability following the application of an artificial stimulus to the uterus of rats sensitized for the decidual cell reaction (Kennedy, 1979a, b). The negative result obtained by Kennedy (1979b) with PGI-2 may be due to the inherent instability of this PG, and it may have not had sufficient time to act before being hydrolysed to 6-oxo-PGF-1 $\alpha$.

Treatment of rats on Days 3 and 4 of pregnancy with indomethacin delayed the appearance of uterine 'dye reaction' sites, which normally occurred at 02:00 h on Day 6. 'Dye reaction' sites were visible, however, at 10:00 h on Day 6. Similar results have been reported by Kennedy (1977) who injected indomethacin on Day 5 only. Indomethacin treatment therefore only delayed the increase in capillary permeability. Whether implantation could be delayed indefinitely by continued indomethacin administration requires investigation.

Indomethacin treatment also interfered with the subsequent development of pregnancy. Rats treated on Days 3 and 4 and examined on Day 9 of pregnancy had an absence, or a reduction in number, of implanted blastocysts in spite of the normal number of uterine 'dye reaction' sites seen at 10:00 on Day 6. Uterine weight was significantly reduced on Day 9, a finding also reported by Kennedy (1977) for Day 8, while Horan (1971) has reported a reduction in uterine weight on Day 7 in rats treated with sodium salicylate during early pregnancy. The treatment of rabbits during early pregnancy with indomethacin, or if they have previously been actively immunized against PGE-2 or PGF-2 $\alpha$, similarly produces retardation of embryonic growth and resorption (Elzayat \& Stylos, 1974; El-Banna, Sacher \& Schilling, 1976; Hoffman, 1978).

In some of the rats treated with indomethacin the implanting blastocysts were bunched at the cervical end, as previously observed by Kennedy (1977). Local increases in uterine PG production within a uterine horn could be responsible for the normally even spacing of the blastocysts at implantation. In the indomethacin-treated rats, plasma progesterone concentrations were significantly reduced at Days 6-9 of pregnancy. Kennedy (1977) using a lower indomethacin dose, reported no difference in plasma progesterone concentrations on Day 5. Indomethacin may have lowered progesterone levels either by a direct action on the ovary, or by reducing luteotrophic support. It is not clear whether the fall in progesterone levels occurred as a result of the failure of normal pregnancy, or vice versa, or, indeed, whether there was any connection at all. Further investigations into the action of indomethacin are needed to clarify these points.

This work was performed during the tenure of an M.R.C. studentship to C.A.P. and an M.R.C. programme grant to Professor E. W. Horton. Authentic prostaglandins were kindly provided by the Upjohn Co., Kalamazoo, U.S.A., and indomethacin by Merck, Sharpe and Dohme Ltd, Hoddesdon, U.K. The gas chromatogram-mass spectrometer was purchased with a grant provided by the Wellcome Trust.

\section{References}

Dey, S.K. \& Dickmann, Z. (1974) Oestradiol-17 $\beta$ hydroxysteroid dehydrogenase activity in preimplantation rat embryos. Steroids 24, 57-52.

Dickmann, Z. \& Dey, S.K. (1974) Steroidogenesis in the preimplantation rat embryo and its possible influence on morula-blastocyst transformation and implantation. J. Reprod. Fert. 37, 91-93.

Dighe, K.K., Emslie, H.A., Henderson, L.K., Rutherford, F. \& Simon, L. (1975) The development of antisera to prostaglandins B-2 and F-2 $\alpha$ and their 
analysis using solid-phase and double antibody radioimmunoassay methods. Br. J. Pharmac. 55, $503-514$.

Dighe, K.K., Jones, R.L. \& Poyser, N.L. (1978) Development of a radioimmunoassay for measuring 6-oxo-PGF-1 a. Br. J. Pharmac. 63, 406P.

El-Banna, A.A., Sacher, B. \& Schilling, E. (1976) Effect of indomethacin on egg transport and pregnancy in the rabbit. $J$. Reprod. Fert. 46, 375-378.

Elzayat, S. \& Stylos, W.A. (1974) The effect of circulating antibodies on reproduction in rabbits with special reference to the placenta. Endocrinology 95, 1642-1648.

Fenwick, L., Jones, R.L., Naylor, B., Poyser, N.L. \& Wilson, N.H. (1977) Production of prostaglandins by the pseudopregnant rat uterus in vitro, and the effect of tamoxifen with the identification of 6keto-prostaglandin F-1 $\alpha$ as a major product. $B r . J$. Pharmac. 59, 191-199.

Flower, R.J. (1976) The role of prostaglandins in parturition with special reference to the rat. In The Fetus and Birth (Ciba Fdn Symp. No. 47 n.s.), pp. 297-309. Eds J. Knight \& M. O'Connor. Elsevier, Amsterdam.

Ham, E.A., Cirillo, V.J., Zanetti, M.E. \& Kuehl, F.A., Jr (1975) Estrogen directed synthesis of specific prostaglandins in uterus. Proc. natn. Acad. Sci. U.S.A. 72, 1420-1424.

Hoffman, L.H. (1978) Antifertility effects of indomethacin during early pregnancy in the rabbit. Biol. Reprod. 18, 148-153.

Horan, A.H. (1971) The suppression of inflammatory edema at the nidation site by sodium salicylate and nitrogen mustard in the rat. Fert. Steril. 22, 392-397.

Kennedy, T.G. (1977) Evidence for a role of prostaglandins in the initiation of blastocyst implantation in the rat. Biol. Reprod. 16, 286-291.

Kennedy, T.G. (1979a) Prostaglandins and increased vascular permeability resulting from the application of an artificial stimulus to the uterus of the rat sensitised for the decidual reaction. Biol. Reprod. 20, $560-567$

Kennedy, T.G. (1979b) Does prostaglandin I-2 mediate the increased endometrial vascular permeability which results from application of the deciduogenic stimulus to the sensitised rat uterus? Biol. Reprod. 20 (Suppl. 1), 99A.

Kennedy, T.G. \& Zamecnik, J. (1978) The concentra tion of 6-oxo-PGF-1 $\alpha$ is markedly elevated at the site of blastocyst implantation in the rat. Prostaglandins 16, 599-605.

Maule Walker, F.M. \& Poyser, N.L. (1978) The metabolism of prostaglandins by the guinea-pig uterus with particular reference to corpus luteal maintenance in early pregnancy. Br.J. Pharmac. 62, 177-183.

Mitchell, S., Poyser, N.L. \& Wilson, N.H. (1977) Effect of p-bromophenacyl bromide, an inhibitor of phospholipase A-2, on arachidonic acid release and prostaglandin synthesis by the guinea-pig uterus in vitro. Br. J. Pharmac. 59, 107-113.

Moncada, S., Gryglewski, R., Bunting, S. \& Vane, J.R. (1976) An enzyme isolated from arteries transforms prostaglandin endoperoxide to an unstable substance that inhibits platelet aggregation. Nature, Lond. 263 , 663-665.

Naylor, B. \& Poyser, N.L. (1975) Effect of oestradiol and progesterone on the in vitro production of prostaglandin F-2 $\alpha$ by the guinea-pig uterus. $B r . J$ Pharmac. 55, 229-232.

Pepe, J.G. \& Rothchild, I. (1974) A comparative study of serum progesterone levels in pregnancy in various types of pseudopregnancy in the rat. Endocrinology 45, 275-279.

Poyser, N.L. \& Scott, F.M. (1980) Prostaglandin and thromboxane production in vitro by the rat uterus and ovary during the oestrous cycle. J. Reprod. Fert. 60, 33-40.

Shaikh, A.A. (1971) Estrone and estradiol levels in the ovarian venous blood from rats during the estrous cycle and pregnancy. Biol. Reprod. 5, 247-307.

Wiest, W.G., Kidwell, W.R. \& Balogh, K.J. (1968) Progesterone catabolism in rat ovary: A regulatory mechanism for progestational potency during pregnancy. Endocrinology 82, 844-854.

Wlodawer, P., Kindahl, H. \& Hamberg, M. (1976) Biosynthesis of prostaglandin F-2 $\alpha$ from arachidonic acid and prostaglandin endoperoxides in the uterus. Biochim. Biophys. Acta 431, 603-614. 